\title{
MEDICALIZAÇÃO DA SOCIEDADE E SUAS RELAÇÕES COM A INDÚSTRIA CULTURAL
}

\author{
Medicalization of society and its relations with the Cultural Industry
}

Rafaella Oliveira Resende Vergílio - UFJ/Brasil

Rosely Ribeiro Lima - UFJ/Brasil

\begin{abstract}
RESUMO: Estudos sobre o uso da medicalização vêm se destacando nos debates sobre saúde e educação nas últimas décadas, e pesquisas sobre o assunto ainda se fazem recentes e necessárias. O presente artigo é resultado de uma pesquisa bibliográfica e documental que objetivou refletir sobre as relações existentes entre o fenômeno da medicalização na sociedade e o conceito de Indústria Cultural, por meio da análise de artigos, livros, documentos, filmes/documentários e música. Inicialmente foi apresentado o significado do processo de medicalização, de forma a evidenciar como este fenômeno se instala na sociedade brasileira; posteriormente, foi exposto o conceito de Indústria Cultural, resgatando a teoria proposta por Adorno e Horkheimer; e por fim, foram construídas as possíveis relações entre medicalização e Indústria Cultural. Neste estudo, a medicalização é vista como um dos produtos trabalhados pela Indústria Cultural, por meio da mídia e dos esforços perpetrados pela indústria farmacêutica, o medicamento é divulgado e vendido enquanto alternativa para a redução do sofrimento psíquico e físico; contexto que precisa ser combatido para uma melhor problematização dos mecanismos de controle social para continuar na construção de uma conscientização sobre os problemas individuais e sociais, que precisam ser entendidos perante aos interesses econômicos de específicos grupos sociais.
\end{abstract}

Palavras-Chave: Educação. Indústria Cultural. Medicalização. Saúde.

ABSTRACT: Studies on the use of medicalization have been highlighted in debates on health and education in recent decades, and research on the subject is still recent and necessary. This article is the result of a bibliographic and documentary research that aimed to reflect on the existing relationships between the phenomenon of medicalization in society and the concept of Cultural Industry, through the analysis of articles, books, documents, films / documentaries and music. Initially, the meaning of the medicalization process was presented, in order to show how this phenomenon is installed in Brazilian society; later, the concept of Cultural Industry was exposed, rescuing the theory proposed by Adorno and Horkheimer; and finally, the possible relationships between medicalization and Cultural Industry were built. In this study, medicalization is seen as one of the products worked by the Cultural Industry, through the media and the efforts perpetrated by the pharmaceutical industry, the medicine is divulged and sold as an alternative to reduce psychological and physical suffering; context that needs to be tackled to better problematize the mechanisms of social control to continue building awareness about individual and social problems, which need to be understood in view of the economic interests of specific social groups.

Keywords: Education. Cultural Industry. Medicalization. Health.

Educação, Psicologia e Interfaces, Volume 4, Número 3, p. 1-15, Julho/Setembro, 2020.

ISSN: 2594-5343. DOI: 10.37444/issn-2594-5343.v4i3.298 


\section{INTRODUÇÃO}

O dinamismo social fomentado pelo processo econômico produz potencialidades de trabalho e de inovação, mas também gera inúmeros problemas como o desemprego, o aumento das desigualdades sociais, o consumo excessivo, além de problemas psíquicos que afetam grandes grupos populacionais. É dentro desse complexo contexto que se insere o crescente aumento do uso de medicamentos pela população.

Conforme dados de 2018 do Conselho Federal de Farmácia, disponíveis no site cff.org.br, existem 87.794 farmácias e drogarias privadas no Brasil, além de outras que são públicas, homeopáticas e hospitalares, estimando que existe uma farmácia para cada 3.300 habitantes, sendo os brasileiros grandes consumidores de medicamentos. O marketing e o fácil acesso na aquisição de medicamentos são alguns dos fatores que promovem o consumo indiscriminado de medicamentos em diversos países, inclusive no Brasil.

Além dos problemas no sistema de saúde, considerando a dificuldade existente no acesso ao atendimento médico, o consumo de medicamentos também está diretamente relacinado a cultura que existe no país do hábito da automedicação; facilitada pela representação social que a farmácia é um estabelecimento comercial como outros que vendem mercadorias de livre escolha, levando a população a um possível risco à saúde.

Ademais, atrelado a este fenômeno, pesquisadores puderam notar que essa temática possui uma forte ligação com a ampliação dos serviços médicos, além de um progresso de ordem capitalista, manifestado no amadurecimento e revigoramento do complexo médico-industrial, amplificando assim seus mecanismos de controle social (CARVALHO et. al., 2015). Tal informação leva à reflexão de que o processo de medicalização em si poderia ter fortes relações com o conceito de Indústria Cultural, ideia que se exemplifica na publicação do Comitê Nacional para Promoção do Uso Racional de Medicamentos, intitulada Uso de medicamentos e medicalização da vida: recomendações e estratégias, que diz:

Atualmente, pessoas são constantemente incentivadas a resolver os problemas sociais utilizando medicamentos, e com a ajuda das propagandas de medicamentos nos meios de comunicação, disponibilizadas a todo o momento, é fortalecida a ideia de que utilizar medicamento é sempre bom, quando isso não é verdade. Vale salientar que a indústria farmacêutica investe mais em

Educação, Psicologia e Interfaces, Volume 4, Número 3, p. 1-15, Julho/Setembro, 2020.

ISSN: 2594-5343. DOI: 10.37444/issn-2594-5343.v4i3.298 
marketing do que em pesquisa e desenvolvimento. (BRASIL, MINISTÉRIO DA SAÚDE, 2018, p.13).

Diante dessa reflexão, faremos um recorte nas causas que levam ao consumo indiscriminado de medicamentos, escolhendo trabalhar com uma perspectiva macrossocial para compreender suas influências perante o fenômeno da medicalização. Diante da compreensão da existência de um hábito social e com base no conceito de Indústria Cultural apresentado por Adorno e Horkheimer (1947), o presente artigo busca analisar o fenômeno da medicalização na sociedade, de forma a compreendermos as relações de consumo dos indivíduos com o seu processo de saúde/doença. A relevância desse trabalho está em se juntar aos esforços para ampliar a compreensão referente a complexidade do sistema, do qual os meios de comunicação em massa fazem parte e que influenciam hábitos e colocam em risco a saúde da população.

\section{MATERIAL E MÉTODO}

Este estudo se trata de uma pesquisa bibliográfica e documental, e buscou por meio da análise de artigos, livros, filmes/documentários e música, refletir sobre as relações existentes entre o fenômeno da medicalização da sociedade com o conceito de Indústria Cultural. Para isto, o artigo foi apresentado da seguinte forma: inicialmente foi esclarecido o significado do termo medicalização, de forma a evidenciar como o presente fenômeno se instala na sociedade brasileira; posteriormente, foi exposto o conceito de Indústria Cultural, resgatando a teoria proposta por Adorno e Horkheimer; e por fim, foram expostas as relações que os dois termos apresentados possuem entre si, auxiliando numa maior compreensão desse processo.

A análise bibliográfia permitiu localizar os significados das categorias aqui discutidas, a pesquisa documental favoreceu na apresentação de possíveis dados gerais sobre o tema, como também exemplificar alguns achados perante documentários e música. Pelo exposto, a pesquisa está vinculada aos estudos qualitativos das Ciências Humanas. Para Minayo (1994, p. 24), os autores e pesquisadores que seguem a abordagem da pesquisa qualitativa se preocupam em "[...] compreender e explicar a dinâmica das relações sociais [...] e também com a compreensão das estruturas e instituições como resultados da ação humana objetivada".

Educação, Psicologia e Interfaces, Volume 4, Número 3, p. 1-15, Julho/Setembro, 2020.

ISSN: 2594-5343. DOI: 10.37444/issn-2594-5343.v4i3.298 
Portanto, a pesquisa é qualitativa, pois busca fundamentos teóricos que possibilitaram a construção de compreensões acerca do fenômeno da medicalização contido na prática social. Além disto, as referências utilizadas sobre a Indústria Cultural consideram a subjetividade do ser humano e buscam compreender a multiplicidade de dimensões que envolvem determinados processos contidos nas vivências das pessoas.

\section{RESULTADOS E DISCUSSÃO}

Motivados por discussões sobre o uso indiscriminado da medicalização pela população, mergulhamos em uma literatura que nos permitiu fazer seleções para que pudéssemos vislumbrar o objeto investigativo. Apresentamos, neste item, contribuições de autores sobre o significado da medicalização e da Indústria Cultural. Escolhemos organizar a redação em itens para destacar a importância de cada um para a construção de nosso entendimento, que permitiu uma possível relação entre ambas as categorias.

\subsection{Medicalização da Sociedade}

Os estudos acerca da temática medicalização vêm ganhando destaque nas últimas décadas, tendo em vista que tal fenômeno se torna cada vez mais crescente ao longo do tempo. Por isto, ao abordar este assunto, se faz pertinente a realização de um esclarecimento acerca dos conceitos que este termo carrega. Os autores Zorzanelli, Ortega e Bezerra Júnior (2014) apresentam algumas de suas principais definições, sendo que a primeira delas aponta que o termo medicalização se refere à definição de um determinado comportamento como um problema médico de forma a permitir que tal comportamento possua alguma proposta de tratamento por parte da Medicina. Já a segunda definição apresentada, e também a mais recente delas, possui uma grande proximidade da primeira, considerando a medicalização como a descrição de “[...] um processo pelo qual problemas não médicos passam a ser definidos e tratados como problemas médicos, frequentemente em termos de doenças ou transtornos [...]" (p. 1860), e como consequência disto, percebese uma exacerbação do uso do medicamento para o tratamento de dificuldades em todas as esferas da vida.

Nesse sentido, fazendo um reflexão acerca do paradoxo entre "moderação e excessos", os pesquisadores Telles, Costa e Severiano (2009) destacam a prescrição e o consumo de medicamentos de modo intensificado como algo marcante na cultura 
ocidental, tendo em vista de que nessa sociedade existe uma evidente propagação de ideias que incluem "[...] a não-necessidade do sofrimento, a cura rápida promovida pela medicalização e a aparente infalibilidade do poder médico que fazem com que os fármacos tenham a capacidade de moderar a vida de milhares de pessoas" (p.4). Tais ideias incentivam ainda mais o uso da medicação, o que pode levar a ações preocupantes como no caso da automedicação, do consumo indiscriminado e exagerado de remédios, a prescrição indevida, o vício, entre outros problemas.

Além disso, Alves e Bragaglia (2014) apresentam que a medicalização se fez como uma ferramenta importante dentro de um cenário onde as demandas do mercado de trabalho e da própria sociedade na atualidade são acentuadas por uma busca perversa pelo aumento da produtividade e da eficiência nos serviços, destacando a impossibilidade de parar para descansar, considerando que estes seriam os pré-requisitos para se alcançar o sucesso num ambiente carregado de competitividade. Partindo desta demanda, a indústria farmacêutica se atentou em criar produtos que pudessem atingir esses objetivos num menor espaço de tempo, com o mínimo de esforço.

Conforme apontado por Rocha et. al. (2019), os discursos em favor da medicalização foram alimentados pela própria ascensão da indústria farmacêutica e pelo saber médico, o qual não seria questionado por pessoas mais leigas. Com este fortalecimento, é notável que paulatinamente nos deparamos com diagnósticos cada vez mais precoces e por vezes questionáveis de doenças graves como Depressão, Ansiedade, e Transtorno de Déficit de Atenção e Hiperatividade (TDAH). Em decorrência da condição de fluidez e rapidez em que sociedade se apresenta, nota-se uma expressiva negação de sentimentos como tristeza e sofrimento, pois estes passam a ser entendidos como sentimentos de irregularidade que se enquadram no campo da anormalidade e, consequentemente, passam a ser medicalizados. Assim, verifica-se que a medicação se apresenta como forma de anestesiar o mal-estar gerado pelo contexto atual (ROCHA et. al., 2019).

Diante disso, Telles, Costa e Severiano (2009) defendem que os medicamentos em si, tal como uma ferramenta, são imparciais, mas sua “[...]relação com o poder e a ideologia da Indústria farmacêutica não[...]” (p.4), isto é, é inegável que as medicações são de fato capazes de exercerem suas principais funcionalidades, e que também se fazem 
muito necessárias em determinados casos, no entanto, quando se analisa os mecanismos mercadológicos e as técnicas que as gerenciam, elas recebem um novo sabor.

E é justamente por conta do que foi exposto acima que o presente estudo buscou compreender as relações que o fenômeno da medicalização possui com o conceito de Indústria Cultural, partindo da suspeita de que este último tenha fortes conexões com o fortalecimento do processo medicalizante.

\subsection{A Indústria Cultural}

Assim como a medicalização, para explanarmos sobre a questão da Indústria Cultural é imprescindível que seja esclarecido sobre o que se trata esse conceito e os significados que o mesmo carrega. Apresentado por Adorno e Horkheimer (1985), o conceito de Indústria Cultural aparece pela primeira vez na obra "Dialética do Esclarecimento". A finalidade destes autores era a de apresentar um termo pelo qual representasse a ação de transformação de elementos culturais em bens de consumo. Desta forma, assim como exposto por Morais, Pascoal e Severiano (2011) a cultura deixaria de ser cultura a partir do momento em que se integrasse à lógica do mercado, tornando-se assim, valor de troca, dado que os bens culturais passariam a ser produzidos de acordo com as demandas de mercado, não possuindo mais como propriedade os anseios dos artistas.

Diante disso, Medrano e Valentim (2001) apontam que o produto cultural vai perdendo todo o seu prestígio e valor a partir do momento em que são reduzidos à meras mercadorias, e é em tais mercadorias que são reduzidas todas as relações sociais. Deste modo, toda cultura ou arte é dissolvida e transformada em um valor de troca. Os autores ainda explicam que uma das principais ferramentas da Indústria Cultural utilizadas para acessar toda a população com maior facilidade, é a televisão, tendo em vista de que a mesma está presente não só nos lares de cada pessoa, como também se adentra nas escolas, seja por meio programas governamentais, ou até mesmo por meio de informações levadas pelos profissionais e alunos que ali se encontram.

Além da televisão, a Indústria Cultural conta com alguns outros aliados, como por exemplo: a internet, a música, a literatura e até mesmo o próprio cinema. Com estes diferentes tipos de recursos, torna-se possível criar necessidades que até o momento eram inexistentes ao público que as consomem. Utiliza-se desta forma, variados tipos de

Educação, Psicologia e Interfaces, Volume 4, Número 3, p. 1-15, Julho/Setembro, 2020. ISSN: 2594-5343. DOI: 10.37444/issn-2594-5343.v4i3.298 
elementos visuais, contendo um marketing perfeito e um grande poder de convencimento, portando uma boa linguagem de sedução, levando os indivíduos a aderirem e consumirem o produto em questão. Para além disto, a Indústria Cultural pode também corroborar com a permanência de alguns estereótipos ligados a questões preconceituosas, raciais, de classes sociais, entre outras, deformando assim, sua percepção acerca da realidade. (MEDRANO; VALENTIM, 2001).

Nesse cenário, os autores Telles, Costa e Severiano (2009) apontam que algumas classes ou grupo de classes dominantes, na tentativa de direcionar e atingir os interesses do seu público para o produto que se oferece, utilizam-se de artifícios, como: variados meios de produção e comunicação, e até mesmo mecanismos de lazer, de forma a exercer um controle bem sutil, e ao mesmo tempo rigoroso. A sutileza é tamanha que tal direcionamento passa a ser desapercebido, deixando uma impressão de que a escolha do consumidor foi feita de forma livre e espontânea. Por conseguinte, os consumidores chegam a interpretar suas escolhas como únicas, individuais, personalizadas, enquanto na realidade, existe uma padronização velada de uma escolha que foi ocultamente direcionada diante de uma suposta proposta cheia de possibilidades. Partindo desse contexto, Adorno e Horkheimer (1985) denunciavam que a violência da sociedade industrial havia se instalado nos homens permanentemente, de maneira que até mesmo os indivíduos mais distraídos consumiriam abertamente os produtos propostos pela indústria cultural.

Além disto, Adorno e Horkheimer (1985) esclarecem que o que verdadeiramente se pretende apresentar com a Indústria Cultural é a existência de uma forma de cultura fabricada de maneira velada pela indústria para ser consumida pela massa, sendo assim, por mais que possa parecer que essa cultura partiu de um público em geral, ela efetivamente foi criada pelo mercado. Assim como exposto por Adorno (1987), “[...] o consumidor não é rei, como a indústria cultural gostaria de fazer crer, ele não é o sujeito dessa indústria, mas seu objeto[...]” (p. 288). Partindo disso, Morais, Pascoal e Severiano (2011) concluem que não se trata de "[...] uma cultura que se origina nas massas, mas algo produzido a partir de uma racionalidade industrial para as massas [...]” (p.6).

Vale ressaltar que a Indústria Cultural não é considerada somente como um mero elemento da produção capitalista, Morais, Pascoal e Severiano (2011) registram que a mesma foi projetada para ocupar o espaço de determinadas funções sociais, estando ela

Educação, Psicologia e Interfaces, Volume 4, Número 3, p. 1-15, Julho/Setembro, 2020.

ISSN: 2594-5343. DOI: 10.37444/issn-2594-5343.v4i3.298 
presente nos locais de lazer dos indivíduos, de forma que os mesmos convivam com ela sem poderem tomar consciência da complexidade da realidade pela qual estão sendo submetidos. Deste modo, os trabalhadores reproduziriam as relações sociais pelas quais eram submetidos desde a época da revolução industrial. Entende-se que se a sociedade apresenta os mesmos hábitos de sempre, desde quando o capitalismo de instaurou, sem nenhum tipo de questionamento ou reflexão, ela permanecerá a mesma.

Partindo dessa concepção, Medrano e Valentim (2001) apontam que um dos objetivos da Indústria Cultural seria o de justamente ludibriar e alienar os homens da sociedade moderna, fazendo com que os mesmos se mantenham ocupados com seus produtos e não percebam todas as injustiças e falhas do sistema capitalista. Assim sendo, exerce uma função de estimular e cativar as massas, dirigindo-as ao consumo, apresentando-lhe uma proposta de felicidade e de completude, fazendo com que o consumidor se transforme em um ser acrítico.

Dificilmente algum cidadão estará imune aos inúmeros efeitos da Indústria Cultural, por isto, o presente trabalho se faz importante, na medida em que visa apresentar a medicalização como um dos fenômenos da atualidade que pode ser alimentado pela indústria. Assim, a medicalização se apresenta como um mecanismo importante para o controle social.

\subsection{A Medicalização da Sociedade e suas relações com a Indústria Cultural}

Com o aumento da tecnologia e as mudanças recorrentes do mercado globalizado, as grandes organizações passaram a focar todos os seus interesses ao lucro e à competitividade, se preocupando exclusivamente com sua produtividade. Em consequência disto, estando inseridos ou não no mercado de trabalho, os indivíduos passaram a seguir os padrões de uma vida caótica pela qual o que importa é estar sempre disposto e preparado para enfrendar uma jornada de atividades perenes no seu dia a dia.

O mal-estar, a falta de disposição, a dor e qualquer outro tipo de alteração no estado de saúde do indivíduo passam a ser considerados um tipo de fraqueza e ineficiência, sendo estes, alguns dos maiores obstáculos para se alcaçar o sucesso. Diante disto, a indústria farmacêutica se apresenta como a detentora das soluções para estes problemas, visando suprimir essas dificuldades humanas por meio de seus produtos farmacológicos.

Educação, Psicologia e Interfaces, Volume 4, Número 3, p. 1-15, Julho/Setembro, 2020. ISSN: 2594-5343. DOI: 10.37444/issn-2594-5343.v4i3.298 
Partindo dessa realidade, Alves e Bragaglia (2014) confirmam que para que os indivíduos sejam aceitos e atendam às expectadivas do mercado, eles precisam dispor de alguns requisitos básicos, independente do que for preciso ser feito para alcançá-los. Percebendo a necessidade de aprimoramento da performance de cada pessoa, e o desejo do aumento de sua produção sem nenhum impediditivo, a indústria farmacêutica passou a produzir medicamentos que auxiliassem na solução dessas adversidades em um pequeno espaço de tempo, com o mínimo de esforço possível. Alves e Bragaglia (2014) ainda afirmam que “[...] esses medicamentos são recomendados e constantemente consumidos por pessoas que estão inseridas nesta lógica mercadológica pela busca de excelência, resiliência, proatividade e demais características exigidas” (p. 4).

Torna-se viável identificar nesse momento, alguns traços do que anteriormente pôde ser apontado como artifícios da Indústria Cultural, pois é justamente por meio deste conceito, que a indústria farmacológica consegue influenciar as massas ao consumo. Conforme foi evidenciado acima, a Indústria Cultural possui inúmeros mecanismos para atingir a população direcionado-a ao consumo, e para além disto, age de forma a transformar elementos culturais em bens de consumo. Ela utiliza-se dos meios de comunicação, da arte e da mídia para atingir seus objetivos, e essas ferramentas se transformam em um sistema muito eficiente para conquistar os lucros.

Nota-se por meio desse movimento, que aquilo que é disseminado através dos meios interativos de comunicação, como por exemplo a televisão, a rádio e o cinema, se torna tão enraizado na comunidade, que os indivíduos perdem sua capacidade de problematização referente ao que ele consome. Deixa-se de ser questionado o motivo de suas vontades, evidenciando a partir dai um controle das mentalidades partindo da audiência programada pela Indústria Cultural.

Alves e Bragaglia (2014) apontam que a força desse movimento tem sido tão expressiva, que é possível verificar que nas propagandas de medicamentos, os publicitários dão destaque aos fármacos apresentando-os como itens indispensáveis para todo ser humano, mesmo sem nenhuma doença associada ao seu uso, uma vez que se propaga uma visão de que estes auxiliam na promoção de uma vida ativa e tranquila. A medicação é evidenciada como algo que pode estabelecer a normalidade da vida em pequenos comprimidos, os quais podem ser ingeridos por qualquer pessoa que os deseja,

Educação, Psicologia e Interfaces, Volume 4, Número 3, p. 1-15, Julho/Setembro, 2020.

ISSN: 2594-5343. DOI: 10.37444/issn-2594-5343.v4i3.298 
para que esta alcance uma performance de excelência, seja na sua vida profissional, seja na vida pessoal, nos instantes de lazer.

A medicalização tem sido considerada uma prática cada vez mais ordinária, primordialmente quando se refere à medicamentos que não necessitam de receita médica para o acesso. Conforme exposto por Alves e Bragaglia (2014, p. 5):

\begin{abstract}
A publicidade assume o papel do médico e se encarrega de receitar o medicamento, além de apresentar sua serventia e facilidade de uso, a fim de alcançar os objetivos de forma eficaz. A indústria soube observar os hábitos culturais brasileiros para potencializar ainda mais seus resultados, uma vez que a automedicação já faz parte desta cultura, desde os indígenas que se tratavam através de chás.
\end{abstract}

A necessidade de autocuidado e a praticidade de se tratar por meio de receitas caseiras herdadas por gerações perpetua com a prática da indicação de remédios à amigos e familiares. A publicidade auxilia no reforçamento desse processo, na medida em que reafirma a sua eficácia no tratamento rápido de suas dificuldades. Basta fazer com que o consumidor experimente e aprove o produto uma única vez, isso já será suficiente para que o mesmo continue o utilizando sempre que achar necessário além de recomendá-lo para outros indivíduos.

Para além disso, quando a automedicação não funciona, o indivíduo toma a decisão de recorrer ao médico, na esperança de que o mesmo apresentará um tratamento milagroso para auxiliá-lo no enfrentamento do seu problema. Telles, Costa e Severiano (2009) ressaltam que o médico ainda é a figura que representa o poder, sendo ele aquele que irá legitimar e reforçar as ações difundidas pela Indústria farmacêutica. É comum, durante a espera de um atendimento médico, verificar a presença de representantes comerciais de diferentes tipos de laboratório saindo dos consultórios após exibir as novidades que se apresentaram no mercado como proposta de algum tratamento, ampliando suas possibilidades de intervenção. Pode-se dizer que isto ocorre justamente pelo poder prescritivo e curativo que lhes são dados, e pela sua aceitação sem nenhum questionamento. Por conta disto Telles, Costa e Severiano (2009) destacam que neste contexto, “[...]apenas os meios importam - seja na produção, divulgação, prescrição e uso - estando os fins negligenciados ou pouco refletidos" (p.5).

Neste sentido, conforme apresentado por Carvalho et. al. (2015) a Medicina se enquadra dentro da esfera do saber-poder, sendo uma estratégia que procura, por meio de sua experiência prática e do saber científico contraído, elaborar “[...] um campo de ação 
na sociedade que opera sobre os mecanismos de produção de subjetividade dos indivíduos" (p. 1257). Desta forma, os autores destacam a existência de um lado produtivo da medicalização, podendo ela ter a capacidade de criar novas verdades e apresentar novas técnicas para atender às diversas demandas dos indivíduos na sociedade. Diante disto, verifica-se que a produção da subjetividade e as relações de poder se manifestam na prática médica, de modo a influenciar a maneira com que os indivíduos decidem viver, refletir e agir, direcionando, a partir disto, sua realidade.

Outra questão importante a ser levantada sobre este fenômeno é que dentro deste mercado competitivo, a Indústria Farmacêutica trabalha em favor de um projeto maior, que é a tentativa de ser referência no tratamento de determinada doença, e para isto, implementa-se a ideia de "remédio-marca", os quais seriam superiores a qualquer outro produto, sendo resultado de pesquisas científicas elevadas com a promessa de resultados inigualáveis. O investimento para se sobressair no mercado é tamanho, que muitas vezes a preocupação com a saúde do consumidor, que deveria ser o principal foco, é deixada de lado. A marca seria a verdadeira essência do produto, é ela quem dita a sua importância, agrega valores, dá uma identidade ao objeto. O consumidor não estaria preocupado em adquirir o produto mais barato, mas sim aquele que é considerado o mais eficiente no mercado, independente de valores. (TELLES; COSTA; SEVERIANO, 2009).

A partir do que foi exposto até o momento, é inegável as ações da indústria sobre a sociedade e a existência de relações intrínsecas entre os conceitos de medicalização e Indústria Cultural. Ao analisar algumas produções midiáticas que vão de encontro com a medicalização de forma a poder apresentar exemplos da ação da Indústria Cultural na sociedade atual, fez-se relevante destacar duas produções, a primeira se trata de um documentário dirigido por Alison Klayman e produzido pela Netflix Studios e Motto Pictures, intitulado por Take your Pills, lançado em 2018; e a segunda se trata da música Who put the Benzedrine in Mrs. Murphy's Ovaltine?, lançada em 1946, por Harry Gibson.

O documentário americano Take you Pills traduzido para o português como “Tome suas pílulas" se trata de uma produção que apresenta a realidade da população que consome determinados tipos de medicação, mais especificamente estimulantes, para melhorar o seu desempenho no dia a dia, de forma a atuar com uma alta performance em qualquer atividade que se proponha a fazer. Durante toda a produção são apresentados por meio de entrevistas, relatos de profissionais e consumidores contando suas respectivas

Educação, Psicologia e Interfaces, Volume 4, Número 3, p. 1-15, Julho/Setembro, 2020. ISSN: 2594-5343. DOI: 10.37444/issn-2594-5343.v4i3.298 
experiências com a referida medicação. O documentário aborda os estimulantes que mais estão em evidência no mercado mundial conhecidos pelos nomes de Adderall® (Shire), Venvanse ${ }^{\circledR}$ (Shire) e Ritalina ${ }^{\circledR}$ (Novartis), dando ênfase ao Adderall de forma a apresentar seus principais seus efeitos.

Dentre os entrevistados, verifica-se a presença de músicos, atletas, estudantes, escritores e professores, pessoas que se enquadram em profissões cercadas pela cobrança em relação à excelência de seu desempenho no trabalho e no cotidiano. Apesar de apresentar os efeitos negativos do uso indiscriminado da medicação, e alertar para os danos à saúde do consumidor, o documentário dá ênfase aos relatos de experiências positivas em relação ao seu consumo. Durante as entrevistas, visualiza-se pessoas revelando sentir-se satisfeitas em receber diagnósticos como TDA (Transtorno no Déficit de Atenção) e TDAH (Transtorno de Déficit de Atenção e Hiperatividade), por poderem através deles receber receitas que autorizam o consumo de medicações.

No decorrer dos relatos apresentados, os indivíduos participantes das entrevistas descreviam o quanto consideravam incríveis os resultados que as medicações proporcionavam em suas vidas. Entre os benefícios alcançados eram citados: o aumento do foco; energia; concentração; melhora no desempenho e aumento na produtividade; além de descreverem estar se sentindo mais vivos, animados e em alerta. Ao assistir estes tipos de relatos, pessoas que ainda não tiveram contato com a referida medicação se sentem seduzidas e são estimuladas a fazer o uso da mesma.

Quanto à análise da música que foi citada mais acima, Who put the Benzedrine in Mrs. Murphy's Ovaltine?, traduzida por "Quem colocou o Benzedrina no Ovomaltine da Sra. Murphy?” em português, apesar de se tratar de uma produção do século passado, também ilustra o incentivo ao uso do medicamento de forma que ao longo da música, é expresso que ao tomar seu Ovomaltine contendo Benzedrina, a Senhora Murphy passou a dormir melhor e diminuir seu nervosismo, solucionando seus problemas. No decorrer da música o compositor descreve que agora a Senhora Murphy se encontra mais disposta, ela quer dançar, saltar, de modo que ela nunca esteve tão feliz.

Perante esses exemplos apontados anteriormente, como também, pensando nos comportamentos sociais adquiridos e guiados pela Indústria Cultural, o controle social está estabelecido junto ao consumo de medicamentos que estão relacionados com imagens de uma vida saudável, de cura e de bem-estar. Portanto, é importante que se 
problematize essa imagem de salvação, pois o automatismo irracional no consumo de medicamentos provoca o contrário do que dizem as propagandas, fomenta efeitos colateriais graves, acometimento e mal-estar, colocando a vida da população em risco.

\section{CONSIDERAÇÕES FINAIS}

Refletir acerca das influências da Indústria Cultural no cotidiano nos permite ponderar sobre o dinamismo social existente em determinado tempo e espaço, bem como sobre a lógica capitalista que impera na sociedade. A medicalização, nesse contexto, passa a ser vista como um dos produtos a ser proposto e trabalhado pela Indústria Cultural. É por meio da mídia, por intermédio dos esforços perpetrados pela indústria farmacêutica, assim como pelo poder médico e pelos hábitos enraizados no cotidiano que a automedicação se tornou naturalizada. O uso do medicamento passa a ser entendido como uma alternativa eficaz e rápida para redução do sofrimento psíquico e das dificuldades encontradas no dia a dia.

Esses indicaticos, entre outros, mostra a dimensão social do problema da automedicação, é urgente que se construa uma representação social do risco do consumo desinformado dos medicamentos, a incerteza no cuidado à saúde gera resultados duvidosos, precisando, assim, ser combatido. Enquanto um problema social, é preciso que as sociedades atuais busquem uma formação reflexiva e crítica de sua população, perante essas linguagens imagéticas advindas da Indústria Cultural. Neste sentido, a área educacional pode ajudar na tentativa de colaborar com a formação crítica da opinião pública frente à lógica capitalista e fomentar uma formação consciente e emancipadora da sociedade.

\section{REFERÊNCIAS BIBLIOGRÁFICAS}

ADORNO, Theodor W.; HORKHEIMER, Max. Dialética do esclarecimento: fragmentos filosóficos. Rio de Janeiro: Jorge Zahar Editor, 1985.

ADORNO, Theodor W. A indústria cultural. In: COHN, Gabriel. Comunicação e indústria cultural. 5ed. São Paulo, T. A. Queiroz Editor, 1987.

ALVES, Philipe Rabelo; BRAGAGLIA, Ana Paula. Publicidade de Medicamentos: Medicalização da Sociedade. In: Anais Intercom - Sociedade Brasileira de Estudos Interdisciplinares da Comunicação - XIX Congresso de Ciências da Comunicação na Região Sudeste, Vila Velha - ES, 2014. Disponível em: <

Educação, Psicologia e Interfaces, Volume 4, Número 3, p. 1-15, Julho/Setembro, 2020. ISSN: 2594-5343. DOI: 10.37444/issn-2594-5343.v4i3.298 
http://www.portalintercom.org.br/anais/sudeste2014/resumos/R43-0305-1.pdf $>$. Acesso em: 20 dez. 2019.

BRASIL. Ministério da Saúde. Secretaria de ciência, tecnologia e insumos estratégicos. Departamento de assistência farmacêutica e insumos estratégicos. Uso de

Medicamentos e Medicalização da Vida: recomendações e estratégias. Brasília:

Ministério da Saúde. 2018. 33 p. Disponível em:

<http://bvsms.saude.gov.br/bvs/publicacoes/medicamentos_medicalizacao_recomendac oes_estrategia_1ed.pdf >. Acesso em: 28 abr. 2020.

BRZOZOWSKI, Fabiola Stolf; CAPONI, Sandra. Medicamentos Estimulantes: uso e explicações em casos de crianças desatentas e hiperativas. Cadernos Brasileiros de Saúde Mental, Florianópolis, v.7, n.15, p.01-23, 2015. Disponível em: <https://periodicos.ufsc.br/index.php/cbsm/article/view/69013/41517> Acesso em: 20 dez. 2019.

CARVALHO, Sérgio R.; RODRIGUES, Camila de O.; COSTA, Fabrício D. da; ANDRADE, Henrique S. Medicalização: uma prática (im)pertinente?. Physis Revista de Saúde Coletiva, Rio de Janeiro, v. 25, n. 4, p. 1251-1269, 2015. Disponível em: $<$ https://www.scielo.br/pdf/physis/v25n4/0103-7331-physis-25-04-01251.pdf> Acesso em: 20 dez. 2019.

COLLARES, Cecília Azevedo Lima; MOYSÉS, Maria Aparecida Affonso. A transformação do espaço pedagógico em espaço clínico (A Patologização da Educação). Série Ideias, n. 23, São Paulo: FDE, p. 25-31, 1994. Disponível em: < https://midia.atp.usp.br/plc/plc0604/impressos/plc0604_aula01_ativPres_texto3.pdf> Acesso em: 20 dez. 2019.

GIBSON, Harry. Who put the Benzedrine in Mrs. Murphy's Ovaltine?. Estados Unidos, 1946. Disponível em: <https://www.youtube.com/watch?v=rZ5_SyvxDXE>. Acesso em: 20 dez. 2019.

MEDRANO, Eliziara Maria Oliveira; VALENTIM, Lucy Mary Soares. A indústria cultural invade a escola brasileira. Cadernos CEDES, Campinas, v. 21, n. 54, p. 6975, 2001. Disponível em: < https://www.scielo.br/pdf/ccedes/v21n54/5270.pdf> Acesso em: 20 dez. 2019.

MINAYO, Maria Cecília de Souza. (org.). Pesquisa Social: teoria, método e criatividade. Petrópolis: Vozes, 1994.

MORAIS, Rebeca Carvalho de; PASCUAL, Jesus Garcia; SEVERIANO, Maria de Fátima Vieira. "Apaixonados por carros como todo brasileiro"(?): Reflexões frankfurteanas sobre a indústria cultural contemporânea. Estudos e pesquisas em Psicologia, v.11, n.3, p. 873-897, 2011. Disponível em: < http://pepsic.bvsalud.org/scielo.php?script=sci_arttext\&pid=S180842812011000300009\#mailfim> Acesso em: 20 dez. 2019.

ROCHA, Amanda Corrêa; BARRIOS, Nathália da Silva; ROLIM, Paulo Daniel da Silva; ZUCOLOTTO, Marcele Pereira da Rosa. Sofro, logo me Medico: A 
Medicalização da Vida como Enfrentamento do Mal-Estar. Id on Line Revista Multidisciplinar e de Psicologia, v.13, n. 46, p. 392-404, 2019. Disponível em: < https://idonline.emnuvens.com.br/id/article/view/1854> Acesso em: 20 dez. 2019.

TAKE your Pills. Direção de Alison Klayman. Estados Unidos: Netflix Studios; Motto Pictures, 2018. Disponível em: Netflix.

TELLES, Yuri Ximenes Ávilla Siqueira; COSTA, Raphael Marques de Miranda; SEVERIANO, Maria de Fátima Vieira. A Indústria Cultural e a Indústria da Saúde: um olhar frankfurtiano sobre a saúde coletiva, no âmbito da lógica de consumo. In: Anais de trabalhos completos - XV Encontro Nacional da ABRAPSO, Maceió, 2009. Disponível em: < http://www.abrapso.org.br/siteprincipal/images/Anais_XVENABRAPSO/157.\%20a\%2 0ind \%DAstria\%20cultural\%20e\%20ind\%DAstria\%20da\%20sa\%DAde.pdf $>$ Acesso em: 20 dez. 2019.

ZORZANELLI, Rafaela Teixeira; ORTEGA, Francisco; BEZERRA JUNIOR, Benilton. Um panorama sobre as variações em torno do conceito de medicalização entre 19502010. Ciência e Saúde Coletiva, Rio de Janeiro, v. 19, n. 6, p. 1859-1868, 2014. Disponível em: < https://www.scielo.br/pdf/csc/v19n6/1413-8123-csc-19-0601859.pdf> Acesso em: 20 dez. 2019.

\section{Credenciais das autoras}

VERGÍLIO, Rafaella Oliveira Resende. Psicóloga, graduada em Psicologia pela Universidade Federal de Goiás, Regional Jataí (PPGE/UFG/REJ), mestranda em Educação pelo Programa de Pós-Graduação em Educação da Universidade Federal de Jataí (UFJ). (D) Orcid: https://orcid.org/0000-0001-8255-7061. E-mail: rafaella.resende@hotmail.com

LIMA, Rosely Ribeiro. Professora Adjunta na Universidade Federal de Jataí (UFJ), graduada em Pedagogia pela Universidade Federal de Goiás (UFG), mestre e doutora em Educação pela Universidade Federal de Mato Grosso (UFMT). (D) Orcid: https://orcid.org/0000-0002-5223-1826. E-mail: roselyl@gmail.com

Endereço para correspondência: Rafaella Oliveira Resende Vergílio. Rua 14, Quadra 154, Lote 09, Bairro Costa Nery, CEP: 75833-008, Mineiros/Goiás. E-mail: rafaella.resende@hotmail.com

Como citar este artigo (Formato ABNT): VERGÍlLIO, Rafaella Oliveira Resende; LIMA, Rosely Ribeiro. Medicalização da Sociedade e suas relações com a Indústria Cultural. Educação, Psicologia e Interfaces, v. 4, n.3, p.1-15, 2020.

Recebido: 07/05/2020.

Aceito: 20/06/2020. 